\title{
Rising Educational Levels Contribute to Compression of Morbidity. A Multi-State Life Table Analysis of the Netherlands 1995-2015
}

\author{
ANTON E. KUNST, Ph.D., Assistant Professor \\ INEZ M.A. JOUNG, MD, Ph.D., Assistant Professor \\ WILMA J. NUSSELDER, Ph.D., Senior Researcher \\ CASPAR W.N. LOOMAN, MSc, Statistician \\ JOHAN P. MACKENBACH, MD, Ph.D., Professor \\ Department of Public Health, Faculty of Medicine and Health Sciences, \\ Erasmus University, Rotterdam, The Netherlands
}

\begin{abstract}
Objective: This paper assesses whether the future rise in educational levels of the elderly may not only increase life expectancy (LE) but also at the same time contribute to a reduction in life expectancy with disability (LED).

Methods: For each educational level, $L E$ and LED were estimated from multi-state life tables with a 'disabled' and 'non-disabled' state. Basic transition rates were estimated from regression analysis of data of a Dutch longitudinal study. The results per educational level were aggregated to the total population for the years 1995, 2005 and 2015.
\end{abstract}

Results: In 1995, men in the highest educational level had a 0.9 years longer $L E$ and a 5.4 years shorter LED than men in the lowest level. Differences among women were larger (2.0 and 8.3 years). Due to rising educational levels between 1995 and 2015, LE for the total male population would increase by 0.2 years while LED would decrease by 0.5 years. A larger effect was observed for women (0.2 and 1.5 years). 
Conclusion: Rising educational levels of the elderly are likely to contribute to a compression of morbidity over the next decades, especially among women.

Keywords: Health expectancy, Mortality, Disability, Socioeconomic factors, Netherlands, Projection, Multi-state life table

\section{Introduction}

Since about 1940, each new generation enjoyed better access to secondary and tertiary education, and achieved higher educational levels than any previous generation. Over the next decades, as these generations start to enter old age, the educational levels of the elderly population may be expected to increase significantly. For example, among women 60 years and over in the Netherlands, the proportion of those with tertiary education is expected to increase from 16 percent in 2000 to 26 percent in 2020 (Joung et al. 2000). Similar increases may be expected to occur in other European countries as well, even though the timing of the changes will differ by one or two decades.

The forthcoming increase in educational levels is likely to influence the health situation of the elderly populations of European countries. Education may exert its effect, among other ways, by contributing to a further decline in old age mortality. Among generations born after 1940, educational levels are strongly associated with mortality, with the lowest death rates observed for those with tertiary education (Kunst 1997; Mackenbach et al. 1999). This association is likely to reflect a causal effect of education on mortality that is mediated via diverse factors, including the better living conditions and healthier life styles of those who have a higher education (Elstad 2000; Stronks 1997; Valkonen 1987). It is likely that these beneficial effects will persist to some extent when these generations will enter old age. The experience of former generations showed that old age mortality is highly 'plastic' (Vaupel 1997) and that even at ages up to 80 years, the higher educated have better chances to survive 5 or 10 years more (Amaducci et al. 1998; Marmot and Shipley 1996; Martelin, Koskinen and Valkonen 1998).

Thus, the forthcoming rise in educational levels may have the effect of further increasing the life expectancy of the elderly in Europe. The question that immediately follows is whether these additional years of life will be years in good health, or years burdened with disease and disability. This question is not only relevant to the elderly themselves, but also to society at large. The ageing of the populations of European countries is strongly increasing the demand for, and costs of, national health-care services. This increase would be even steeper if the future 
elderly were to spend an increasingly large part of their life with disease and disability.

Some, although not all, studies of past trends suggest that increases in life expectancies may indeed be accompanied by an increase in the number of years that people live with disability (Bone 1995; Bronnum-Hansen 1998; Cambois and Robine 1996; Doblhammer and Kytir 2001; Van de Water, Boshuizen and Perenboom 1996). The additional years of life gained over the past decades were mainly years with disability. In some studies (Bone 1995), increases were observed in the prevalence of mild or moderate forms of disability (e.g. having some problems with climbing stairs) although not for the severest forms (e.g. not being able to climb stairs). This 'expansion of morbidity' occurred both in absolute terms (more years of life with disability) and in relative terms (a larger part of the entire life time with disability).

Uncertain is whether these trends will continue in the future. A main challenge to health policies is to let further increases in life expectancies be accompanied by a decrease in the number of years that elderly have to live with disease or disability. This 'compression of morbidity' could, however, only be achieved by substantial reductions in age-specific rates of disability prevalence among the elderly. Research on 'compression of morbidity' has therefore turned its attention to the identification of specific factors, such as smoking (Barendregt, Bonneux and van der Maas 1997a; Nusselder et al. 2000), that have the potential to contribute to this reduction.

This brings us back to education. Men and women with higher educational levels not only have longer survival, but also enjoy lower prevalence of disability. Recent studies among the elderly in different European countries observed that those who have higher educational levels less often report functional limitations (e.g. difficulties climbing stairs) and more often are able to perform activities of daily living (e.g. bathing) (Amaducci et al. 1998; Breeze et al. 2001; Dahl and Birkelund 1997; Rahkonen and Takala 1998). These educational differences are substantial, and they may perhaps be so large that rising educational levels will contribute to a 'compression of morbidity'.

The purpose of this paper is to assess whether the future rise in educational levels will contribute to either an expansion or a compression of morbidity. This assessment is made for the Netherlands in the period 1995 to 2015. The analysis consists of two steps. First, we use longitudinal data from the 1990s to determine to what extent age-specific rates of mortality and disability prevalence differ according to educational level. Next, we will make projections for the period 1995 to 2015 in order to assess the extent to which rising educational levels will influence mortality and disability prevalence among the elderly. Measures of mortality and 
disability prevalence will be combined into a single measure on the compression of morbidity: 'life expectancy with disability' (LED) (Robine, Romieu and Cambois 1999).

Central in our analysis is the use of multi-state life table (MSLT) techniques (Nusselder 1997). The main advantage of this technique is that mortality and disability prevalence are estimated as two outcomes of the same underlying transition rates, i.e. transitions between the states non-disabled, disabled and dead. Thanks to this approach, the effects of education on mortality and disability prevalence respectively can be estimated using the same data source and the same analytical method. This approach will give a high degree of internal consistency, not only in the estimation of educational differences in LED, but also in the projection of future trends in both mortality levels and disability prevalence.

\section{Material and methods}

\section{The GLOBE study}

Data on transition rates were obtained from the GLOBE study, a longitudinal study of the population of Eindhoven and surroundings. A detailed description of this study is given elsewhere (Mackenbach, van de Mheen and Stronks 1994). A postal questionnaire was sent in 1991 to a random sample of about 27,000 Dutch nationals aged 15-74 years. Persons living in institutions were excluded from this sample, except for the city of Eindhoven (with 40 percent of all respondents), where homes for the elderly were included. The response percentage to this postal questionnaire was 70.3 percent. Of these respondents, 7,677 persons were approached for an oral interview in 1991. In the follow-up, these 7,677 persons received a postal questionnaire in $1993(\mathrm{n}=4496$, i.e. response of $79.4 \%$, after correction for mortality $81.1 \%)$ and in $1995(\mathrm{n}=4105$, i.e. response of $72.4 \%$, after correction for mortality $76.4 \%)$.

Subjects were classified according to the educational level that they had attained by 1991. Three educational levels were distinguished: elementary, lower secondary, and higher (upper secondary or tertiary). The higher levels had to be combined because the number of observations was too small for estimating transition rates.

Information on mortality was obtained from linkage to municipal population registers. Information on disability status was obtained from identical questions in subsequent waves. Persons were considered to be disabled if they were living in an institution or if they indicated that they could not perform, or perform only with serious difficulty, one or more of the following 10 activities of daily living: eating, bathing/showering, (un)dressing, getting in and out of bed or chair, climbing stairs, 
getting outside, walking $400 \mathrm{~m}$, carrying an object of $5 \mathrm{~kg}$, reading newspaper print, and recognising someone's face from 4 meters' distance. In 1991, the complete set of questions on disability was presented to only 2,867 subjects. In 1993 and 1995, these questions were presented to all subjects. Information on disability was lacking or incomplete for 77 (1991), 96 (1993) and 219 (1995) respondents. Complete information on disability and vital status for both 1991 and 1993 was available for 1,988 persons, while complete information for both 1993 and 1995 was available for 3,119 persons. This yielded a total of 5,107 observations.

\section{Estimation of transition rates}

The 5,107 observations were aggregated into groups according to age (2-year groups), gender and educational level. These aggregated data were used to estimate the four transition rates that are needed to construct a MSLT: incidence rates of disability, recovery rates from disability, mortality rates among non-disabled persons, and mortality rates among disabled persons. These rates were estimated using Poisson (log-rate) regression analysis (Nusselder 1997).

In conventional Poisson regression analysis, the rate of one kind of transition (e.g. from alive to dead) is estimated on the basis of information on the number of observed transitions and the number of person-years at risk. However, the MSLT requires estimates for multiple kinds of transitions. In order to distinguish between the transitions within one single regression analysis covering all kinds of transitions, we added the subscripts $i j$ to denote the type of transition, where $i$ refers to the state of origin (e.g. non-disabled) and $j$ refers to the state of destination (e.g. disabled). The extended Poisson model for data on multiple events is specified as follows:

$\log \left(\mathrm{N}_{\mathrm{ij}}\right)=\log \left(\mathrm{R}_{\mathrm{i}}\right)+\alpha_{\mathrm{ij}}+\beta_{\mathrm{ij}} \mathrm{AGE}+\gamma_{\mathrm{ij}} \mathrm{EDU} \quad(\mathrm{i} \neq \mathrm{j})$

where:

$\mathrm{N}_{\mathrm{ij}} \quad=$ the expected number of transitions from state $i$ at the beginning of the interval to state $j$ at the end of the interval

$\mathrm{R}_{\mathrm{i}}=$ the number of person-years at risk for transition from state $i$, which is known as the 'offset parameter' or 'rate multiplier'

$\alpha_{\mathrm{ij}}=$ the constant, i.e. the expected number of transitions during 1 unit of time for the reference values of age and education

$\mathrm{AGE}=$ a continuous variable denoting exact age

$\beta_{\mathrm{ij}}=$ a series of regression coefficients corresponding this age variable

$\mathrm{EDU}=$ a nominal variable with one value for each educational level

$\gamma_{\mathrm{ij}}=\mathrm{a}$ series of regression coefficients corresponding to this education variable 
For the sake of brevity, subscripts denoting 2-year age group and educational level are omitted from the equation. A subscript for sex is absent because the models were fitted for men and women separately.

The number of person-years at risk in state $i$ was calculated by using turn-over tables. The assumption was made that during the time interval of two years, each person could make only one transition, and that this transition occurred in the middle of the time interval. This method is similar to the standard procedure that is used in cause-elimination life tables to estimate 'independent' or 'net' rates to die from specific causes of death.

By treating age as a continuous variable in Poisson regression, age-specific transition rates were smoothed on the basis of assuming an exponential relationship. This procedure is equivalent to smoothing by means of fitting a Gompertz curves. Instead of this exponential model, more complex relationships with age can be modelled. Nusselder (1997) tested whether the observed age-specific transition rates could be fitted better by two alternative curves: the Gompertz-Makeham curve and the Sigmoid curve. Based on her findings, we decided to model age-specific rates of incidence by means of the Gompertz-Makeham curve. Recovery and mortality rates were modelled by the simple Gompertz curve implied in the formula above.

Due to small numbers of deaths among disabled people, no precise estimates could be obtained of educational differences with respect to mortality among disabled. In order to increase statistical power, the assumption was made that relative differences in mortality were the same among disabled and non-disabled subjects.

Tests were made for interaction between age and education. Because no interaction could be demonstrated with statistical significance, interaction terms were not included in the model.

\section{Construction of multi-state life tables}

For each gender and educational level, the regression analyses yielded a series of estimates of age-specific transition rates. These rates were used to construct one MSLT for each gender and educational level separately. The MSLT were constructed using matrix algebra operations in Excel. We used two-year age intervals in the MSLT, which equals the length of the follow-up intervals in the GLOBE study. We started the life table calculations at age 30 . The initial cohort population (the radix) was distributed over the non-disabled and the disabled state according to the prevalence of disability that was observed in the GLOBE study for men and women of 30 and 31 years.

In the GLOBE study, the maximum age was 75 years at the baseline survey, and it was 79 years after four years of follow-up. Thus, our empirical estimates are 
restricted to men and women living before their $80^{\text {th }}$ birthday. Therefore, we closed the MSLT at age 80, and we will present only results that refer to the age range between the $30^{\text {th }}$ and $80^{\text {th }}$ birthday.

\section{Projection of future trends}

The last part of the analyses aimed to estimate the effect of future changes in the educational composition of the population. These estimates were made in two steps. In the first step, projections were made of the distribution of the Dutch population according to age, gender and education in the years 1995, 2005 and 2015. These estimates were obtained from a cohort-component population projection model that took into account differential mortality by educational level. We assumed that these mortality differences were of the same order of magnitude as those observed in this paper (see Tables 1 and 2).

In the second step, life tables were constructed for 1995, 2005 and 2015 separately. For each year, age-specific transition rates for the total population were estimated on the basis of the educational composition of that population. For each year and age group separately, these rates were estimated by weighting the education-specific rates (as estimated on the basis of GLOBE data) by the share of each educational level in the total population in that year and age group.

\section{Results}

Table 1 presents the relative differences between educational levels in age-specific transition rates. The incidence of disability differed according to educational level with statistical significance. For both men and women, incidence rates were about two times as low for upper levels as for elementary education. Recovery rates showed an inverse pattern, with generally higher rates for higher educational levels. Note that, due to the fairly small number of observations, the confidence intervals are wide and the differences cannot be demonstrated with statistical significance. Finally, small and inconsistent differences are observed with respect to the chance that men or women with a specific disability status will die within the next two years.

On the basis of the fitted transition rates, life tables were constructed for each educational level. Figures 1 and 2 present two age-specific measures of the MSLT: the number of survivors (the survival curve) and the absolute number of years lived with disability. These age-specific measures are summarised in Table 2, which compare educational levels in terms of partial life expectancy (LE, the average number of years lived between the $30^{\text {th }}$ and $80^{\text {th }}$ birthday) and the number of years lived with disability (LED, also between the $30^{\text {th }}$ and $80^{\text {th }}$ birthday). 
Figure 1. Survival curves $\left(1_{x}\right)$ of the MSLT population, by educational level.
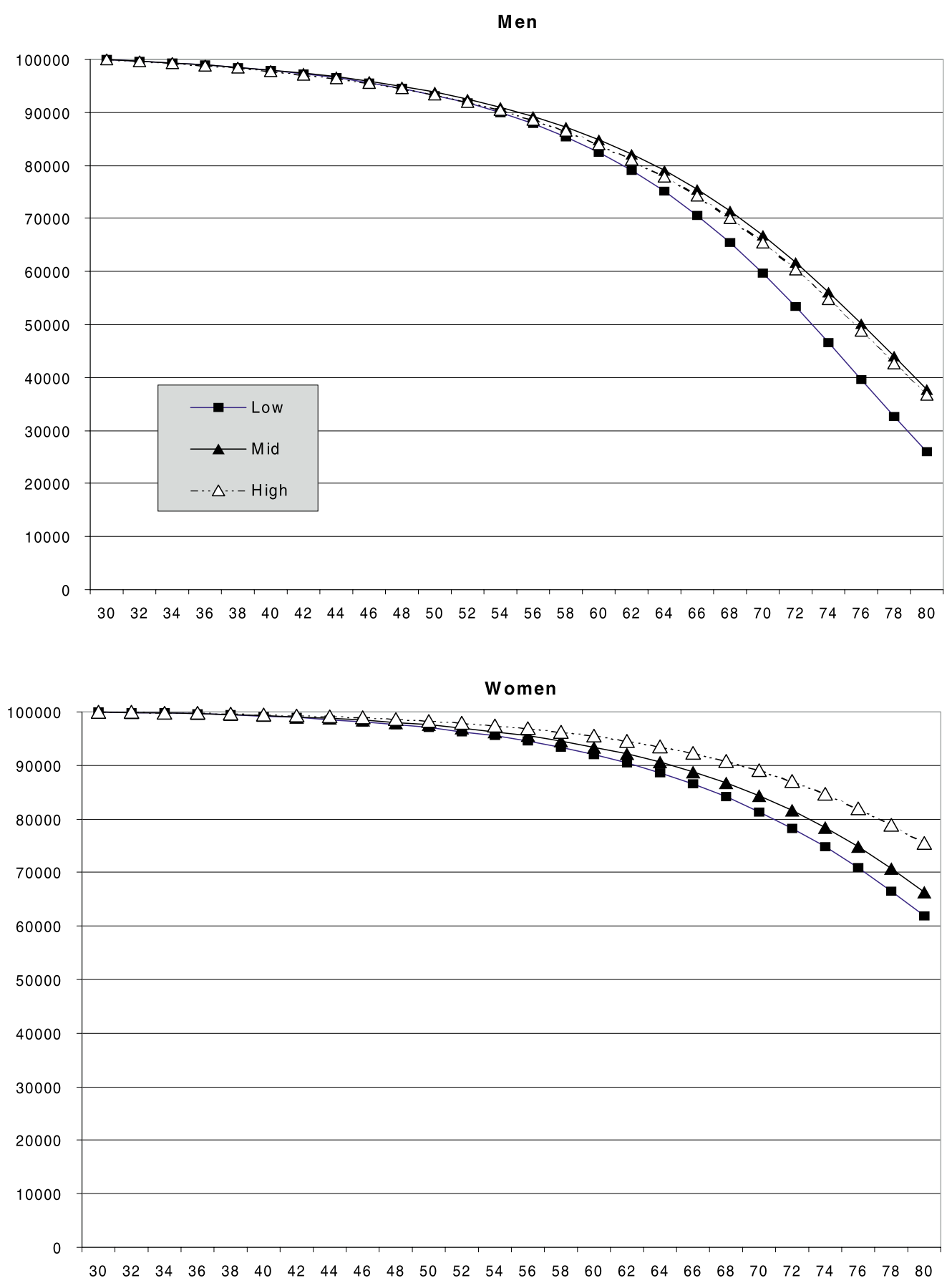
Figure 2. Absolute number of years lived with disability $\left(\mathrm{L}_{\mathrm{x}, \mathrm{dis}}\right)$ in the MSLT population, by educational level.

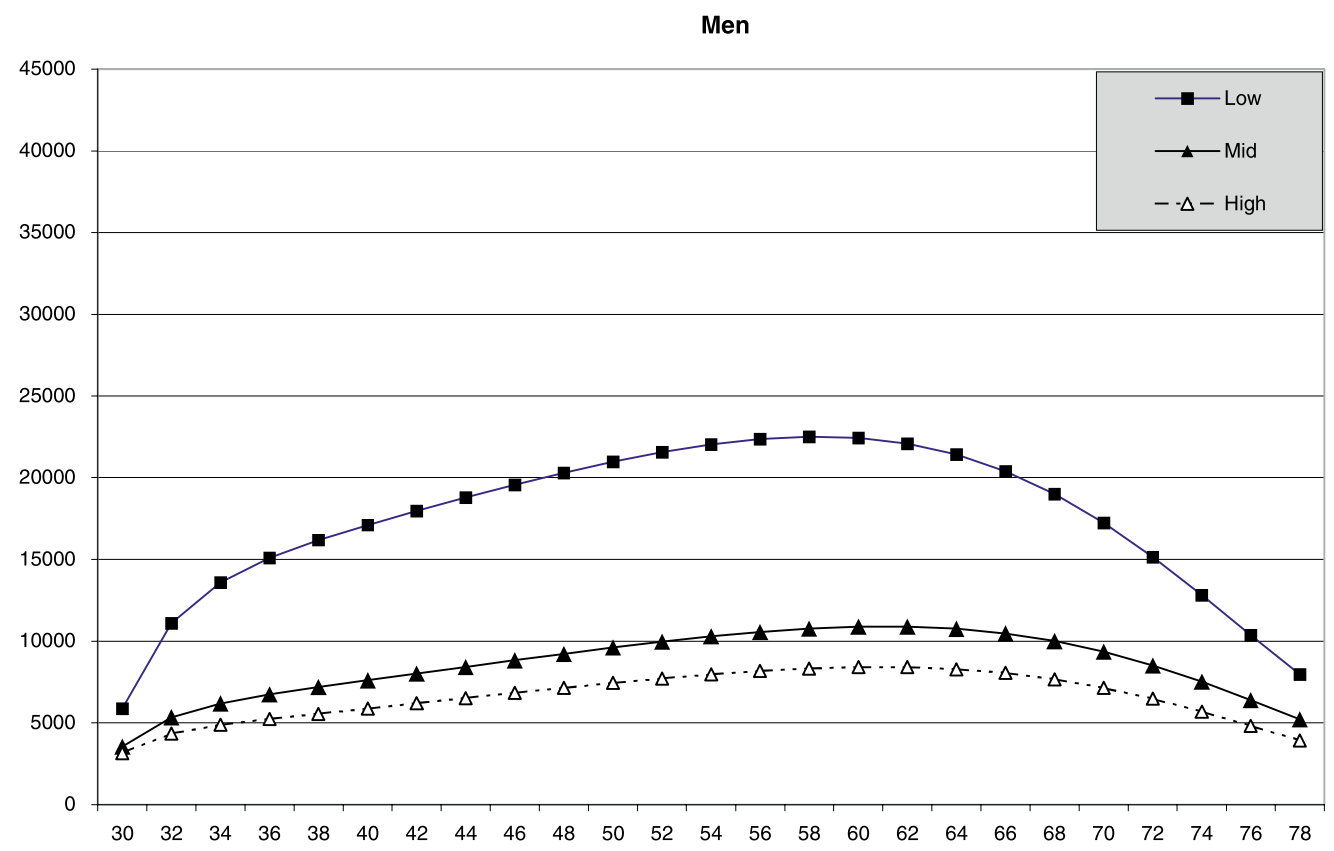

Women

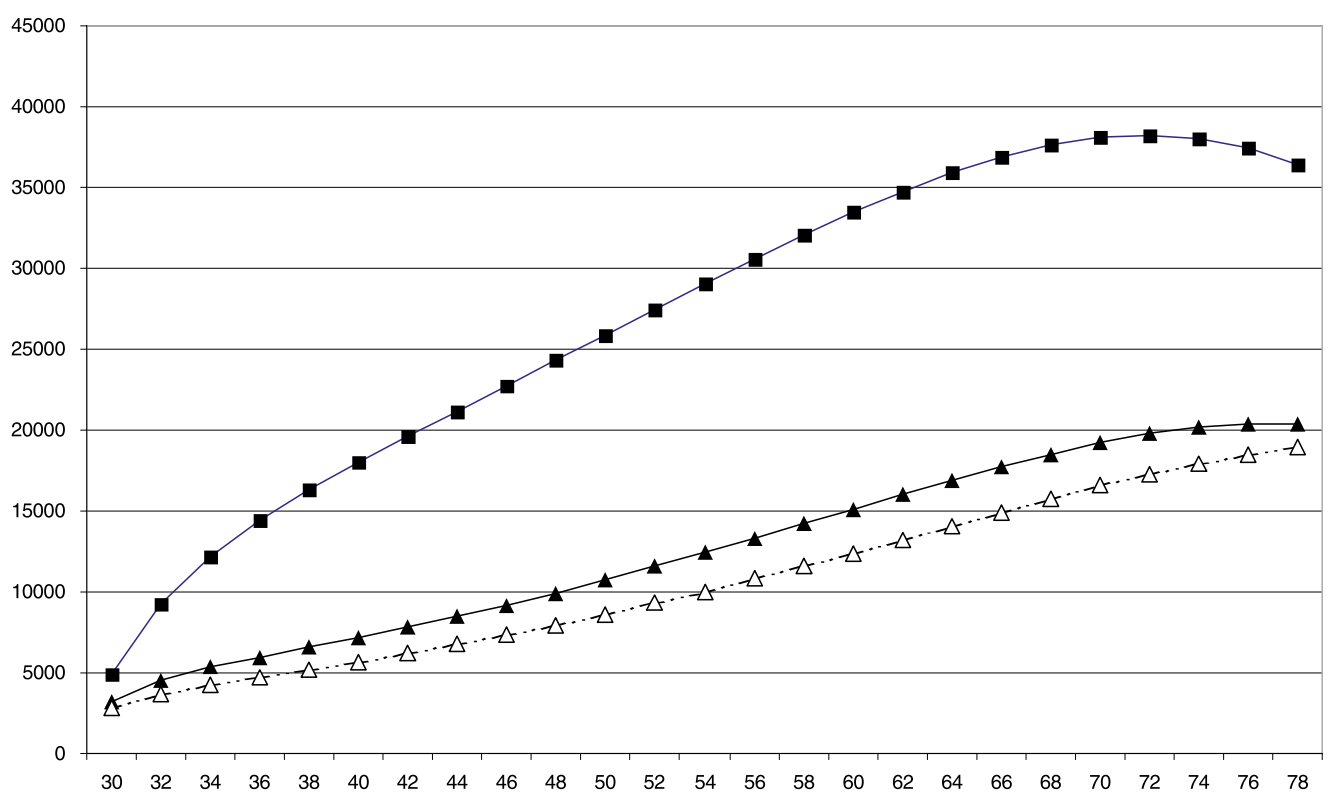


The LE increases with rising educational level among both men and women, except that no difference is observed between men with middle and higher education. It may be surprising to observe educational differences in LE (Table 2) even though there were no differences in state-specific mortality rates (Table 1). The explanation relates to the higher prevalence of disability among the low educated (due to higher incidence rates and lower recovery rates) combined with the much higher mortality of the disabled as compared to the non-disabled (a three- to fourfold mortality difference in most age-sex groups).

Table 1. Regression-based estimates of educational differences in transition rates between non-disabled, disabled and dead.

\begin{tabular}{lcccccc}
\hline & \multicolumn{5}{c}{ Relative risk [a] } \\
\hline & $\begin{array}{c}\text { Elemen- } \\
\text { tary }\end{array}$ & $\begin{array}{c}\text { Lower } \\
\text { second. }\end{array}$ & Higher & $\begin{array}{c}\text { Elemen- } \\
\text { tary }\end{array}$ & $\begin{array}{c}\text { Lower } \\
\text { second. }\end{array}$ & Higher \\
\hline & 1.00 & 0.49 & 0.44 & 1.00 & 0.59 & 0.44 \\
\hline $\begin{array}{l}\text { Incidence } \\
\text { (non-disabled to } \\
\text { disabled) }\end{array}$ & & $0.31-0.67$ & $0.24-0.60$ & & $0.41-0.80$ & $0.30-0.64$ \\
& & & & & & \\
$\begin{array}{l}\text { Recovery } \\
\text { (disabled to }\end{array}$ & 1.00 & 1.25 & 1.48 & 1.00 & 1.85 & 1.81 \\
$\begin{array}{l}\text { non-disabled } \\
\text { (n) }\end{array}$ & $0.60-2.64$ & $0.84-2.22$ & & $1.00-3.44$ & $0.97-2.75$ \\
$\begin{array}{l}\text { Mortality } \\
\text { (non-disabled to } \\
\text { death, and } \\
\text { disabled to death) }\end{array}$ & 1.00 & 0.99 & 1.10 & 1.00 & 1.15 & 0.85 \\
\hline
\end{tabular}

[a] Estimates were obtained by exponentiation of regression coefficients $\mathrm{gg}_{\mathrm{ij}}$ (see Methods section) with elementary level as the reference group. In italic are given 95 percent confidence intervals.

Inverse social gradients are observed for life expectancy with disability (LED), which decreases with increasing educational level. Between 30 and 80 years, men with tertiary education live more than five years less with disability than men with elementary education (3.3 compared to 8.7 years). An even larger difference is observed among women ( 5.5 compared to 13.8 years). The advantage of higher 
educational levels is even more pronounced when expressed in relative terms, i.e. as the proportion of all years that is spent with disability (\%LED). An almost threefold difference between the highest and lowest educational level is observed for both men and women.

Table 2. Summary measures of mortality and disability in the MSLT population, by sex and educational level.

\begin{tabular}{|c|c|c|c|c|c|c|}
\hline & \multicolumn{3}{|c|}{ Men } & \multicolumn{3}{|c|}{ Women } \\
\hline & $\begin{array}{l}\text { Elemen- } \\
\text { tary }\end{array}$ & $\begin{array}{l}\text { Lower } \\
\text { second. }\end{array}$ & Higher & $\begin{array}{c}\text { Elemen- } \\
\text { tary }\end{array}$ & $\begin{array}{l}\text { Lower } \\
\text { second. }\end{array}$ & Higher \\
\hline $\begin{array}{l}\text { LE [a] } \\
\text { average number of } \\
\text { years lived (between } \\
\text { birthdays } 30 \text { and } 80 \text { ) }\end{array}$ & 39.9 & 41.4 & 41.1 & 45.2 & 46.0 & 47.2 \\
\hline $\begin{array}{l}\text { LED: } \\
\text { average number of } \\
\text { years lived with } \\
\text { disability }(30-80)\end{array}$ & 8.7 & 4.3 & 3.3 & 13.8 & 6.5 & 5.5 \\
\hline LED as $\%$ of LE & 21.9 & 10.4 & 8.1 & 30.6 & 14.1 & 11.6 \\
\hline
\end{tabular}

The differences in LE were taken into account in our projections of the future educational composition of the national Dutch population. Results are presented in Table 3. In the age group 30-79 years, the share of elementary education declines between 1995 and 2015, while the share of those with upper secondary or tertiary education increases. Changes are largest for women, especially in the age group 60-79 years. 
Table 3. The educational composition of the Dutch population: the situation in 1995 and projections until 2015.

\begin{tabular}{|c|c|c|c|c|c|c|}
\hline \multirow{3}{*}{$\begin{array}{l}\text { Age group } \\
\text { - year } \\
\text { Transition type }\end{array}$} & \multicolumn{6}{|c|}{$\begin{array}{c}\text { Share in total population } \\
\text { (sum }=100 \% \text { across educational levels) }\end{array}$} \\
\hline & \multicolumn{3}{|c|}{ Men } & \multicolumn{3}{|c|}{ Women } \\
\hline & $\begin{array}{l}\text { Elemen- } \\
\text { tary }\end{array}$ & $\begin{array}{l}\text { Lower } \\
\text { second. }\end{array}$ & Higher & $\begin{array}{l}\text { Elemen- } \\
\text { tary }\end{array}$ & $\begin{array}{l}\text { Lower } \\
\text { second. }\end{array}$ & Higher \\
\hline \multicolumn{7}{|l|}{$30-79$ years } \\
\hline-1995 & 20.4 & 20.8 & 58.8 & 29.4 & 28.3 & 42.3 \\
\hline-2005 & 15.2 & 21.0 & 63.8 & 20.3 & 28.0 & 51.8 \\
\hline-2015 & 10.4 & 20.4 & 69.2 & 14.4 & 26.3 & 59.3 \\
\hline \multicolumn{7}{|l|}{$60-79$ years } \\
\hline-1995 & 31.1 & 21.3 & 47.6 & 47.6 & 27.7 & 24.7 \\
\hline-2005 & 22.0 & 22.2 & 55.8 & 31.9 & 32.8 & 35.3 \\
\hline-2015 & 11.1 & 19.8 & 69.1 & 20.4 & 31.3 & 48.3 \\
\hline
\end{tabular}

Table 4 presents estimates of the extent to which this rise in educational level may contribute to future changes in mortality and disability in the Dutch population. The partial life expectancy for the age range 30 to 80 years (LE) will increase only slightly, by 0.2 years for both men and women. The LED will decrease, by 0.5 years for men and 1.5 years for women between 30 and 80 years. These changes are almost entirely due to the almost equally large changes within the age group 60 to 80 years (right part of Table 4). Education-induced changes were much smaller in the age group 30 to 60 years (results not shown).

Table 4. Projections of the effect of future educational change on MSLT-based measures of mortality and disability.

\begin{tabular}{|c|c|c|c|c|c|c|}
\hline \multirow{3}{*}{$\begin{array}{l}\text { Sex } \\
\text { - year }\end{array}$} & \multicolumn{6}{|c|}{ Measure } \\
\hline & \multicolumn{3}{|c|}{ Age range $30-80$ years } & \multicolumn{3}{|c|}{ Age range $60-80$ years } \\
\hline & LE & LED & LED (\%) & LE & LED & LED (\%) \\
\hline \multicolumn{7}{|l|}{ Men } \\
\hline-1995 & 40.9 & 4.5 & 11.0 & 14.8 & 2.5 & 16.9 \\
\hline-2005 & 41.0 & 4.2 & 10.2 & 14.9 & 2.3 & 15.4 \\
\hline-2015 & 41.1 & 4.0 & 9.7 & 15.1 & 2.0 & 13.2 \\
\hline \multicolumn{7}{|c|}{ Women } \\
\hline-1995 & 46.1 & 8.2 & 17.8 & 17.7 & 5.7 & 32.2 \\
\hline-2005 & 46.2 & 7.3 & 15.8 & 17.8 & 5.0 & 28.1 \\
\hline-2015 & 46.3 & 6.7 & 14.5 & 17.9 & 4.5 & 25.1 \\
\hline
\end{tabular}


The net effect of the opposing trends for LE and LED is a decrease in the proportion of all life years that will be lived with disability (\%LED). In the age group 30 to 80 years, this decrease is moderate for both men (from 11.0 to 9.7 percent) and women (from 17.8 to 14.5 percent). In the age group 60 to 80 years, the \%LED would decrease by about one fifth for men (from 16.9 to 13.2 percent) and women (from 32.2 to 25.1 percent).

In further analysis, our cohort-component projection model was used to extrapolate current patterns and trends beyond 2015. Even though projections more than 20 years ahead are highly speculative, it may be interesting to note that the effects of rising educational levels on survival and disability of men were found to fade away around 2015 (results not shown). For women, this effect persists until at least 2025. If only educational compositions were to change in the future, levels of mortality and disability of women would stabilise between 2030 and 2035, when for example \%LED would approach the 13.3 percent, compared to 14.5 percent in 2015.

\section{Discussion}

The results showed that, in the Netherlands, men and women with higher educational levels live longer lives but live fewer years with disability, as compared to those who have received elementary education only. Projections showed that the rise in educational levels until 2015 may contribute towards the highly desirable situation that an increase in life expectancy is accompanied by a compression of morbidity, not only in relative terms (a smaller proportion of life with disability) but also in absolute terms (less years with disability).

These results may not be surprising to those who are familiar with studies that have compared educational groups by using the Sullivan method. These studies also found that higher educational groups live longer lives but live fewer years with disability (Crimmins and Saito 2001; Kaprio et al. 1996; Sihvonen et al. 1998; Valkonen, Sihvonen and Lahelma 1997). It should be stressed, however, that the Sullivan method has serious methodological weaknesses, the main one being that mortality and disability data come from two entirely different sources, and the mixing of flow and stock measures (Barendregt et al. 1997b). Although the Sullivan method is very useful in summarising mortality and morbidity information in descriptive measures that can easily be communicated to a wider audience (Kunst et al. 2001), much care should be taken to use these measures for analytical purposes, such as causal analysis or the analysis of trends over time (Kunst et al. 2001; Mathers and Robine 1997). 
In recent years, new methods have been explored, and the multi-state life table turned out to be a useful alternative (Crimmins, Hayward and Saito 1994). This method has been applied successfully in studies that aimed to quantify the extent to which compression of morbidity may be achieved by eliminating smoking in the general population (Barendregt et al. 1997a; Nusselder et al. 2000). In this paper, we explored whether this approach can also be used to study compression of morbidity in relation to socioeconomic changes and, more specifically, in relation to the future rise of the educational levels of the elderly. Given the novelty of this application, the methodology and empirical data-base might be improved on several aspects. A careful look at the limitations of the present study is therefore required. These limitations can be summarised into four points.

\section{Limitations inherent to the use of interview survey data}

The empirical data come from a longitudinal follow-up to a health interview survey among the general population. Inherent to the use of most interview surveys are a number of potential data problems, including (a) non-response, (b) exclusion of the institutionalised population and (c) inaccurate self-reports of (changes in) disability. An extensive evaluation of these data problems is made in other studies that are based on the GLOBE study (Schrijvers et al. 1999; Stronks 1997). In general, the net effect of these problems is likely to be an underestimation of educational differences in transition rates, because low-educated people (a) have higher rates of non-response, (b) may have higher chances of becoming institutionalised when sick and (c) tend to underreport health problems more often than high-educated people. As a result, educational differences in mortality levels and disability prevalence are likely to be underestimated. This would imply that the estimates presented in this paper should be regarded as conservative.

\section{Low precision}

Estimates of educational differences in transition rates had wide confidence intervals (Table 1). This implies that the results presented in this paper have low precision, and that they cannot be used to estimate the precise magnitude of the effects of education on compression of morbidity. Lack of precision may probably explain our failure to demonstrate a higher male life expectancy for the upper educational level as compared to the middle level (Table 2). Special concerns merit the estimates of state-specific mortality rates. The estimated mortality rates hardly varied according to educational level, but their 95 percent confidence intervals showed that the educational differences in mortality could be as large as those observed for the incidence and recovery rates (Table 1). Given this possibility, we performed a sensitivity analysis in which we assumed that educational differences in statespecific mortality rates were as large as the observed differences in incidence rates. 
Under this assumption, educational differences in life expectancy are of course larger than those presented in Table 2. More important for the present paper is that educational differences in LED would become slightly smaller, while those in $\%$ LED would remain at the same level as reported in Table 2. Thus, alternative estimates of state-specific mortality rates would not greatly alter our conclusions with regard to compression of morbidity in absolute terms (LED) or relative terms (\%LED).

\section{Exclusion of the oldest old}

Men and women older than 80 years had to be excluded from our calculations due to lack of empirical data in the GLOBE study. One might question whether compression of morbidity would also occur in this age group. If few low-educated people would survive until the $80^{\text {th }}$ or $85^{\text {th }}$ birthday, then it would almost be inevitable that those with a higher education not only live more years at higher ages, but also live more years with disability (i.e. have a higher LED). Empirical data to study this possibility were not available to us. Tentative calculations could, however, be made by extrapolating beyond 80 years the smoothed series of transition rates that we estimated on the data for the 30-79-year-old population. MSLT estimates based on these extrapolated data showed that higher educational levels are associated with more years of disability after about the $85^{\text {th }}$ birthday for men, and after about the $90^{\text {th }}$ birthday for women. These results thus support the expectation that a higher educational level is associated with some expansion of morbidity (in absolute terms) at the end of a cohort's life span. However, our tentative calculations also showed that this expansion was modest compared to the large compression achieved at younger ages.

\section{Restriction to one morbidity indicator}

For the sake of brevity, only one morbidity indicator is analysed in this paper. One might raise the question whether similar results would have been obtained with other measures of the burden of disease or disability. For example, this paper did not focus on serious disability specifically, but instead combined moderate and serious levels. The inclusion of moderate levels was motivated by practical reasons (more positive cases and thus more precision) and by the fact that it was in terms of moderate disability that studies on past trends showed an expansion of morbidity. Nonetheless, it is important in further studies to also focus on serious forms of disability. In general, one might expect to observe a similar effect of education on compression of morbidity, because associations with educational level are observed also for more serious forms of disability (Geurts and Kunst 1997; Kunst et al. 1998). However, the results are not easily predictable, especially because serious disability is much more concentrated in higher ages than is moderate disability. 
Although this list of four limitations may not be complete, it suffices to demonstrate that more work is needed to produce detailed and accurate estimates. Even though the results of this exploratory study suggest that higher education is associated with compression of morbidity, the magnitude of this effect is not known. In addition, it is yet uncertain to what extent this effect varies by gender, age group and morbidity indicator. Fortunately, increasingly more longitudinal studies are becoming available in European countries, including panel studies, follow-ups to national health interview surveys, disease registers, and linkage-based registries on for example work disablement. With these data-bases, the simultaneous effects of education on mortality and morbidity can be assessed in much more depth than was possible up to now.

In this paper, the associations that were observed for the 1990s were fed into a cohort-component projection model in order to assess the effects of the future rise of the educational levels of the elderly population. A key assumption is this projection was that relative inequalities in mortality and disability remained unchanged over the 20 years of the projection period. This assumption was made on the basis of the evidence from several European countries that educational differences in mortality have been highly persistent over the past decades, and that relative inequalities do not show any tendency to decline (Kunst et al. 2001; Martikainen, Valkonen and Martelin 2001). However, one cannot exclude the possibility that relative inequalities will finally start to narrow in the near future. Although this would not challenge our fundamental point that rising educational levels may contribute to a compression of morbidity, this contribution would be smaller if a narrowing of health inequalities would indeed happen (Nusselder et al. 2000). This uncertainty is one more reason for us to refrain, at the current state of knowledge, from stating how large this contribution might be.

As in any projection, our results should not be interpreted as a prediction of the most likely trends in the future. Future trends depend on more factors than the rise in educational level only, and the effects of other factors may by far outweigh those of education. Some studies observed that an expansion of disability occurred in the past, and perhaps one should fear that these trends would persist into the future. Our analysis only aimed to single out the role that education can play. The positive effects that we observed are similar to those observed in studies on smoking, which concluded that a compression of morbidity might occur if smoking prevalence rates would decline. The main message of both our and these other studies is that future trends might be more favourable than they were in the past.

The common findings for both education and smoking raise the question of why both determinants could contribute to a compression of disability, and in which respects they differ from the determinants that have dominated the past trends towards an expansion of moderate disability. Our MSLT analyses provide clues to 
an answer. Higher educational groups were found to have lower LED thanks to substantially lower incidence rates combined with higher recovery rates. In a series of scenario analyses, Nusselder showed that a decrease of incidence rates combined with an increase in recovery rates would result in a relative compression of disability at all ages, and an absolute compression until the age of about 85 years (Nusselder 1997). Real-life examples were not given in Nusselder's simulations, but it now appears that higher educational groups represent a good example of this compression scenario.

Such real life examples are rare. It seems that most interventions and secular changes contribute to an expansion of morbidity. An expansion occurs if statespecific mortality rates change more rapidly than incidence and recovery rates. Many interventions in health care have this effect due to curative interventions that are aimed specifically at improving the prognosis of fatal diseases, or due to preventive interventions that have a greater impact on fatal diseases (e.g. cancer, heart disease) than on diseases with low case fatality but a high disability burden (e.g. arthritis). The distinguishing feature of education is that (a) it is associated with incidence as well as with the case-fatality of fatal diseases and (b) it is associated with both non-fatal diseases as well as fatal diseases. The latter point can be illustrated by data from health interview surveys from several European countries (Kunst et al. 1998). For example, data from a Dutch national survey showed large (more than twofold) educational differences in the prevalence of many disabling diseases, including diseases whose case-fatality is high (e.g. stroke, heart disease), intermediate (e.g. diabetes mellitus, bronchitis, epilepsy, ulcers) or low (e.g. chronic spinal disorders, arthritis) (Geurts and Kunst 1997).

Even though there are strong links between education and the incidence and recovery from many diseases, we should note that these links are indirect and dependent on the role played by intermediate factors such as living conditions, social support, and health behaviours (Elstad 2000; Stronks 1997; Valkonen 1987). A recent Finnish analysis suggested that the positive effect of education on survival is to a large extent mediated by the higher level of wealth and income that those with higher education enjoy (Kunst, Pensola and Valkonen 2000). Therefore, if the oncoming rise in educational levels of the elderly is not accompanied by a parallel increase in their living standards, the contribution to compression of morbidity may be modest. If, on the other hand, living standards will improve to a similar extent, or even more, compression of morbidity might be even larger than would be expected on the basis of the rise in educational levels. Therefore, the rise in educational level should not be taken as a promise that compression would happen anyhow, but instead as a challenge that we must face. When the elderly will not only have higher educational levels, but can also enjoy better living conditions, the next decades might show a definite trend towards compression of morbidity. 


\section{Acknowledgements}

The work for this paper was financed by grants from the Priority Program on Population Research of the Netherlands Organisation for Scientific Research ("NWO"), and from the Fifth Framework Programme on 'Quality of Life and Management of Living Resources' of the European Commission (contract no. QLK61999-02161).

\section{References}

Amaducci, L., S. Maggi, J. Langlois, N. Minicuci, M. Baldereschi, A. Di Carlo, and F. Grigoletto. 1998. Education and the risk of physical disability and mortality among men and women aged 65 to 84: the Italian Longitudinal Study on Aging. The Journals of Gerontology. Series A, Biological Sciences and Medical Sciences 53:M484-90.

Barendregt, J. J., L. Bonneux, and P. J. van der Maas. 1997a. The health care costs of smoking. The New England Journal of Medicine 337:1052-7.

Barendregt, J. J., L. Bonneux, and P. J. van der Maas. 1997b. How good is Sullivan's method for monitoring changes in population health expectancies? Journal of Epidemiology and Community Health 51:578-9.

Bone, M. R. 1995. Health expectancy and its uses. London: HMSO.

Breeze, E., A. E. Fletcher, D. A. Leon, M. G. Marmot, R. J. Clarke, and M. J. Shipley. 2001. Do socioeconomic disadvantages persist into old age? Self-reported morbidity in a 29-year follow-up of the Whitehall Study. American Journal of Public Health 91:27783.

Bronnum-Hansen, H. 1998. Trends in health expectancy in Denmark, 1987-1994. Danish Medical Bulletin 45:217-21.

Cambois, E., and J. M. Robine. 1996. An international comparison of trends in disabilityfree life expectancy. Developments in Health Economics and Public Policy 5:11-23.

Crimmins, E. M., M. D. Hayward, and Y. Saito. 1994. Changing mortality and morbidity rates and the health status and life expectancy of the older population. Demography 31:159-75.

Crimmins, E. M., and Y. Saito. 2001. Trends in healthy life expectancy in the United States, 1970-1990: gender, racial, and educational differences. Social Science and Medicine 52:1629-41.

Dahl, E., and G. E. Birkelund. 1997. Health inequalities in later life in a social democratic welfare state. Social Science and Medicine 44:871-81.

Doblhammer, G., and J. Kytir. 2001. Compression or expansion of morbidity? Trends in healthy-life expectancy in the elderly Austrian population between 1978 and 1998. Social Science and Medicine 52:385-91.

Elstad, J.I. 2000. Social inequalities in health and their explanations. Oslo: Norwegian Social Research (NOVA).

Geurts, J. J. M., and A. E. Kunst. 1997. Illustrations of the effect of data specifications on observed inequalities in morbidity. In: Morbidity and mortality data: problems of comparability, edited by G Wunsch and A Hancioglu, pp. 115-142. Ankara (Turkey): Hacettepe University.

Joung, I. M., A. E. Kunst, E. van Imhoff, and J. P. Mackenbach. 2000. Education, aging, and health: to what extent can the rise in educational level relieve the future health (care) 
burden associated with population aging in the Netherlands? Journal of Clinical Epidemiology 53:955-63.

Kaprio, J., S. Sarna, M. Fogelholm, and M. Koskenvuo. 1996. Total and occupationally active life expectancies in relation to social class and marital status in men classified as healthy at 20 in Finland. Journal of Epidemiology and Community Health 50:653-60.

Kunst, A. E. 1997. Crossnational comparisons of socioeconomic differences in mortality. Rotterdam: Erasmus University.

Kunst, A. E., V. Bos, J. P. Mackenbach, and EU Working Group on Socioeconomic Inequalities in Health. 2001. Monitoring socioeconomic inequalities in health in the European Union: guidelines and illustrations. Rotterdam: Erasmus University.

Kunst, A. E., A. E. J. M. Cavelaars, F. Groenhof, J. J. M. Geurts, J. P. Mackenbach, and EU Working Group on Socioeconomic Inequalities in Health. 1998. Socioeconomic inequalities in morbidity and mortality in Europe: a comparative study. Rotterdam: Erasmus University.

Kunst, A. E., T. Pensola, and T. Valkonen. 2000. Education and premature mortality in Finland in 1991-1995. Helsinki / Rotterdam: University of Helsinki / Erasmus University.

Mackenbach, J. P., A. E. Kunst, F. Groenhof, J. K. Borgan, G. Costa, F. Faggiano, P. Jozan, M. Leinsalu, P. Martikainen, J. Rychtarikova, and T. Valkonen. 1999. Socioeconomic inequalities in mortality among women and among men: an international study. American Journal of Public Health 89:1800-6.

Mackenbach, J. P., H. van de Mheen, and K. Stronks. 1994. A prospective cohort study investigating the explanation of socio- economic inequalities in health in The Netherlands. Social Science and Medicine 38:299-308.

Marmot, M. G., and M. J. Shipley. 1996. Do socioeconomic differences in mortality persist after retirement? 25 year follow up of civil servants from the first Whitehall study. British Medical Journal 313:1177-80.

Martelin, T., S. Koskinen, and T. Valkonen. 1998. Sociodemographic mortality differences among the oldest old in Finland. The Journals of Gerontology. Series B, Psychological Sciences and Social Sciences 53:S83-90.

Martikainen, P., T. Valkonen, and T. Martelin. 2001. Change in male and female life expectancy by social class: decomposition by age and cause of death in Finland 197195. Journal of Epidemiology and Community Health 55:494-9.

Mathers, C. D., and J. M. Robine. 1997. How good is Sullivan's method for monitoring changes in population health expectancies? Journal of Epidemiology and Community Health 51:80-6.

Nusselder, W. J. 1997. Compression or expansion of morbidity? A life table approach. Rotterdam: Erasmus University Rotterdam.

Nusselder, W. J., C. W. Looman, P. J. Marang-van de Mheen, H. van de Mheen, and J. P. Mackenbach. 2000. Smoking and the compression of morbidity. Journal of Epidemiology and Community Health 54:566-74.

Rahkonen, O., and P. Takala. 1998. Social class differences in health and functional disability among older men and women. International Journal of Health Services 28:511-24.

Robine, J. M., I. Romieu, and E. Cambois. 1999. Health expectancy indicators. Bulletin of the World Health Organization 77:181-5.

Schrijvers, C. T., K. Stronks, H. D. van de Mheen, and J. P. Mackenbach. 1999. Explaining educational differences in mortality: the role of behavioral and material factors. American Journal of Public Health 89:535-40.

Sihvonen, A. P., A. E. Kunst, E. Lahelma, T. Valkonen, and J. P. Mackenbach. 1998. Socioeconomic inequalities in health expectancy in Finland and Norway in the late 1980s. Social Science and Medicine 47:303-15. 
96

Stronks, K. 1997. Socioeconomic inequalities in health: individual choice or social circumstances? Rotterdam: Erasmus University.

Valkonen, T. 1987. Social inequality in the face of death. In: European Population Conference, pp. 201-262. IUSSP / EAPS / FINNCO. Helsinki: Central Statistical Office of Finland.

Valkonen, T., A. P. Sihvonen, and E. Lahelma. 1997. Health expectancy by level of education in Finland. Social Science and Medicine 44:801-809.

Van de Water, H. P., H. C. Boshuizen, and R. J. M. Perenboom. 1996. Health expectancy in the Netherlands. European Journal of Public Health 6:21-28.

Vaupel, J. W. 1997. The average French baby may live 95 or 100 years. In: Longevity: to the limits and beyond, edited by J-. M. Robine, J. W. Vaupel, B. Jeune, and A. Allard, pp. 11-28. Berlin: Springer-Verlag. 